\title{
Vascular Epithelial Growth Factor Measurement
}

National Cancer Institute

\section{Source}

National Cancer Institute. Vascular Epithelial Growth Factor Measurement. NCI

Thesaurus. Code C82043.

The determination of the amount of vascular epithelial growth factor present in a sample. 